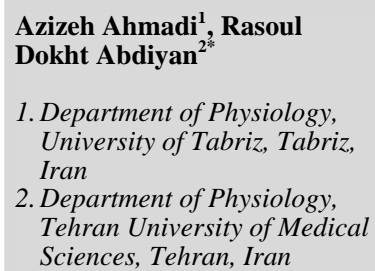

1. Department of Physiology, University of Tabriz, Tabriz, Iran

2. Department of Physiology, Tehran University of Medical Sciences, Tehran, Iran

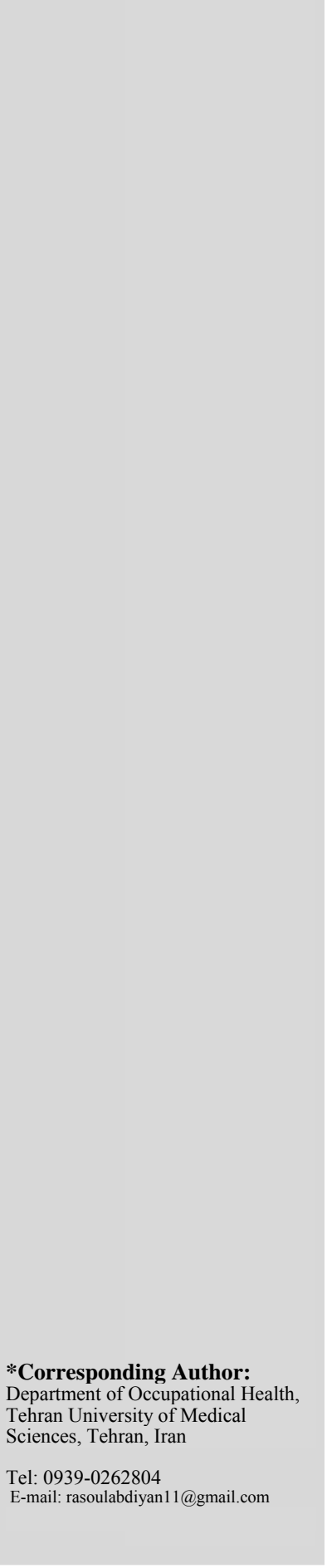

\section{Compare the Effects of Two High Intense Interval Training (HIIT) Protocol on Some Hem Rheological Markers in Young Overweight and Obese Women}

\author{
Received: 31 Feb. 2017 ; Accepted: 6 Jul. 2017
}

\section{Abstract}

Background: Manipulation of training variables such as intensity, volume and training session's frequency could affect the exercise compatibility and dynamicity these carry out different physiological adaptations. The purpose of this study is determining the effect of two types high intensity training (HIIT) on some hem rheological factors in young overweight and obese women.

Methods: 24 girls with age 25/75 $\pm 1 / 18$ y, height: $161 / 29 \pm 4 / 23 \mathrm{~cm}$, weight $74 / 51 \pm 6 / 27 \mathrm{~kg}$, fat $30 / 70 \pm 2 / 23 \%$, BMI $28 / 66 \pm 1 / 89 \mathrm{~kg} / \mathrm{m} 2$ voluntarily participated in this study and randomly divided into three experimental HIIT1 group $(n=8)$, HIIT2 group $(n=8)$ and control group $(\mathrm{n}=8)$. The subjects of the group HIIT1 in each session running 30 seconds in four sets with 19 to 20 the rate of perceived exertion (RPE) Borg scale and two minutes of rest between sets. $\mathrm{HIIT}_{2}$ group running four sets of $60 \mathrm{~s}$ with the same intensity and four minutes rest between sets, training protocol performed three times a week and as long as four weeks. 48 hours before and 48 hours after exercise, blood samples were taken. For analyzing data, use Mixed between-within Subjects analysis of variance in level of $(p>0.05)$.

Results: Results showed in levels of RBC, MCV, MCH, hematocrit, hemoglobin wasn't significantly variation and also difference between groups was not significant $(p>0.05)$. RDW was significantly changed only in HIIT2 group $(p<0.05)$ and there was no difference between groups $(p>0.05)$. MCHC in each the experimental groups showed significantly changes, the difference between groups was significant only between each experimental groups with control $(p<0.01)$.

Conclusion: according to the results, it can be said that short term HIIT (30 s) in comparison with midterm HIIT (60 s) probably accompanied with slightly hemolysis side effects.

Keywords: Red blood cell count, Mean corpuscular volume (MCV), mean corpuscular hemoglobin (MCH), Mean corpuscular hemoglobin concentration (MCHC), Red Cell Distribution Width (RDW). 


\section{مقايسه تأثير اجراى دو نوع يروتكل تمرين تناوبى شديد (HIIT) بر برخى شاخصهاى هماتولوزيكى خون دختران غيرفعال دار ايى اضافهوزن و جاق ناق}

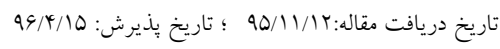

حكيله

زمينه و هدف: دستكارى متغيرهاى تمرينى جون شدت، حجم و تكرار جلسات تمرين مى تو اند بـر سـازكارى و بويـايى

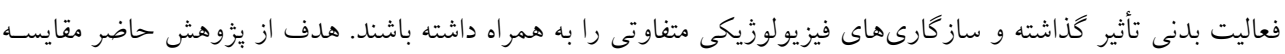

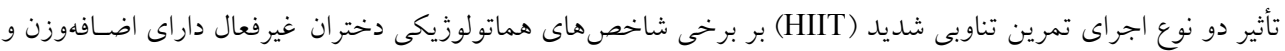

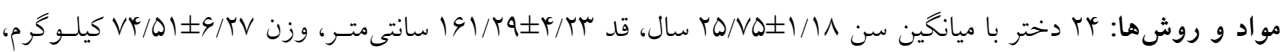

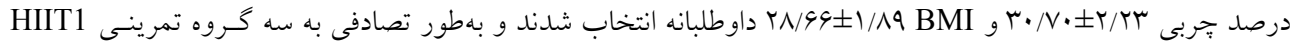

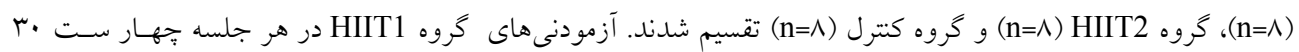

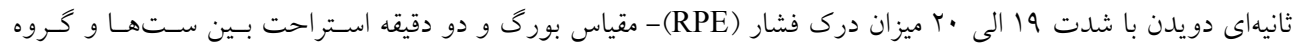

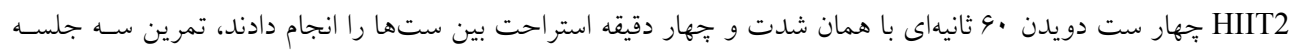

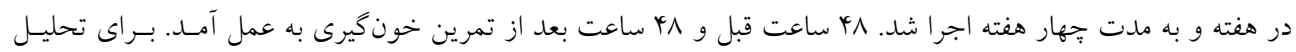

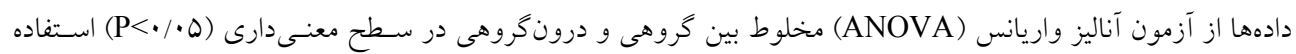

يافتها: در متغيرهاى شمارش كلبولهاى قرمز، HGB و HCT،MCH ،MCV ،غييرات معنى دارى مشاهده نشد، همجنين

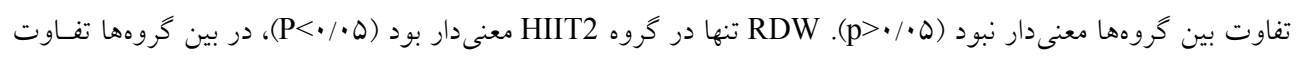

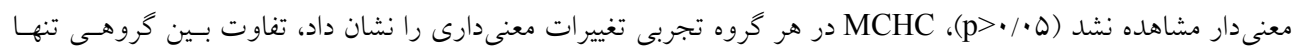

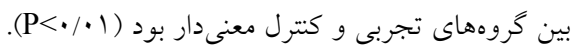

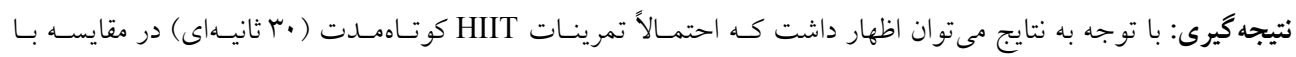
ميانمدت ( •4 ثانيهاى) با عوارض هموليزى اندكى همر اه هستند.

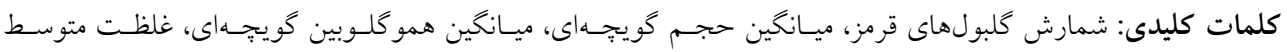

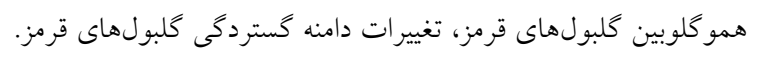

عزيزه احمدى'، رسول دخت عبديان" 'دانشجوى دكتـراى فيزيولوزي ورزشسى،

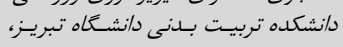
تبريز، ايران

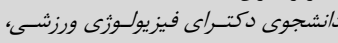

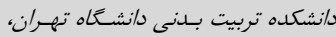
تهران، /يران تريت بن 


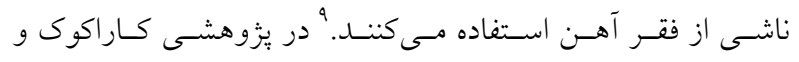

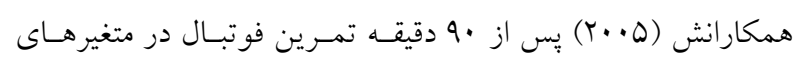
HGB و MCV

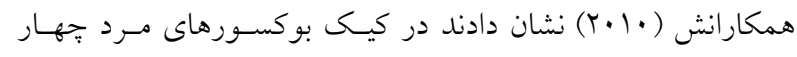

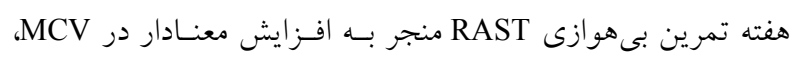

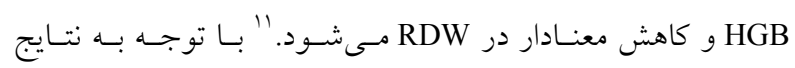

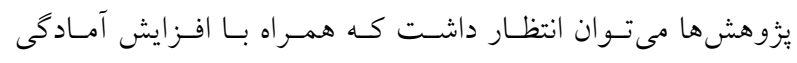

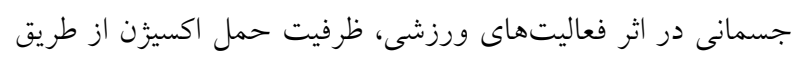

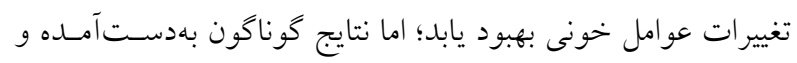

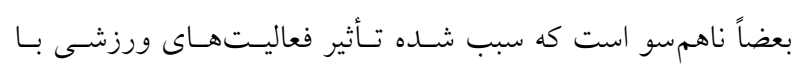

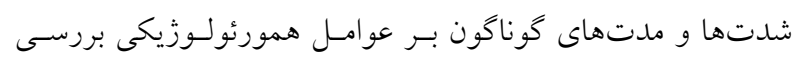

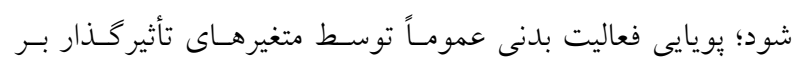

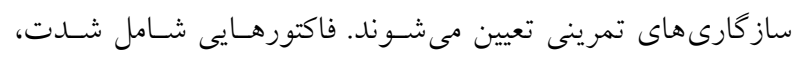

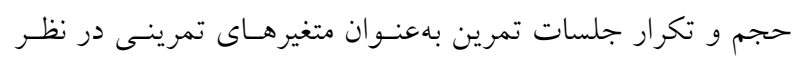

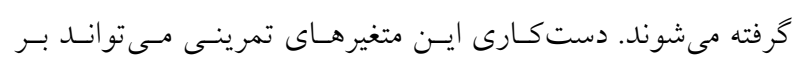

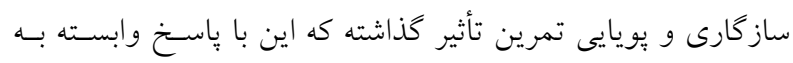

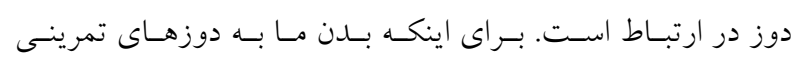

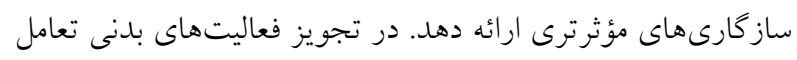

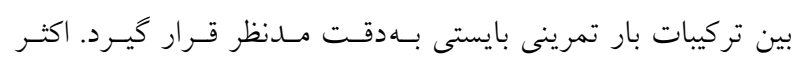

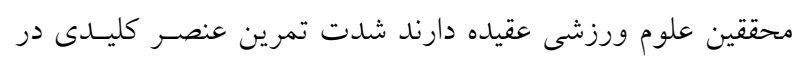

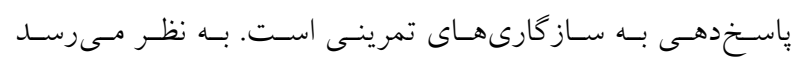

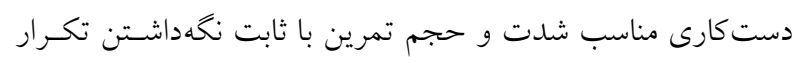

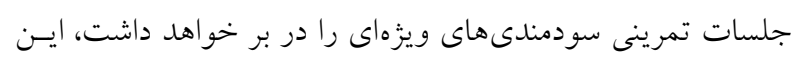

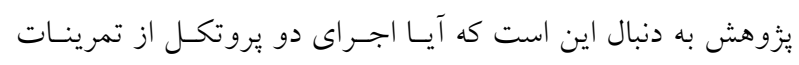

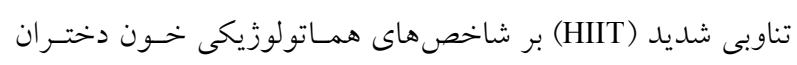

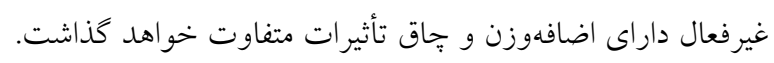

\section{مواد و روشها}

اين مطالعه از نوع كاربردى و روش يزوهش حاضر از نوع نيمه

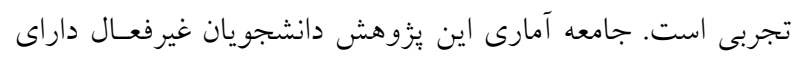

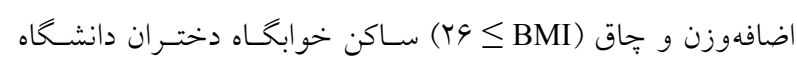

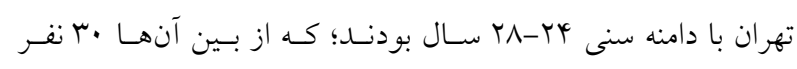

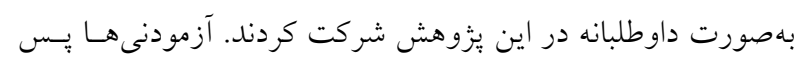

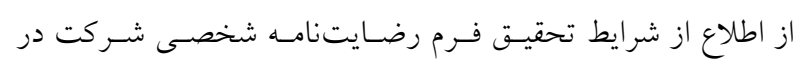

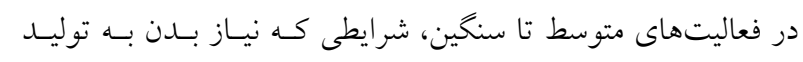

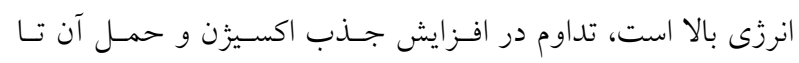

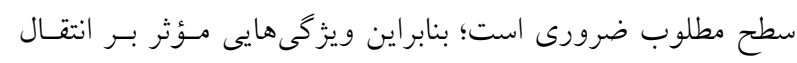

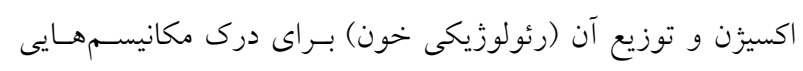

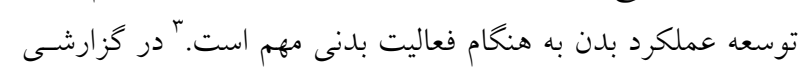

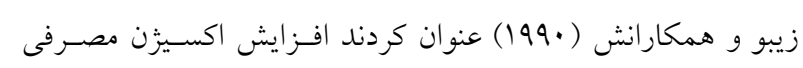

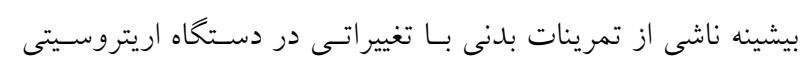

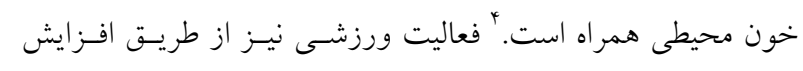

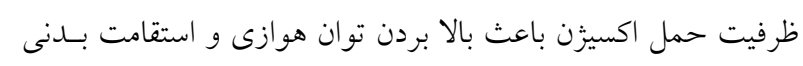

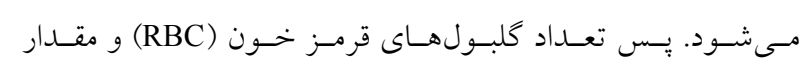

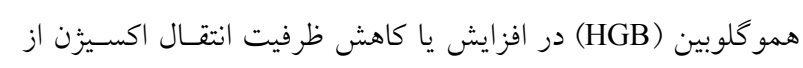

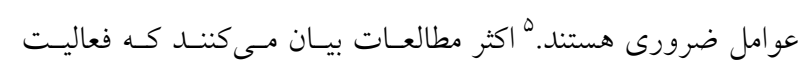

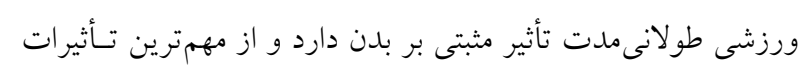

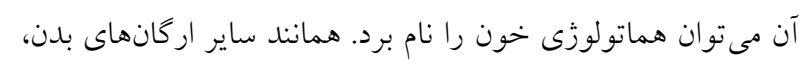

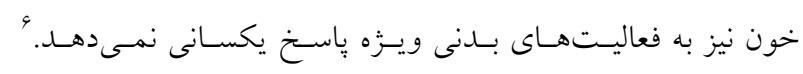

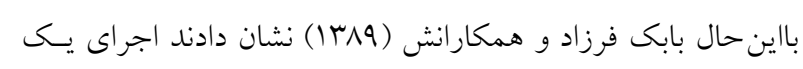

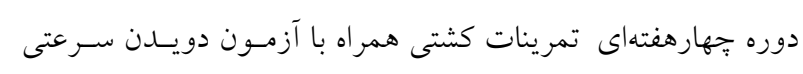

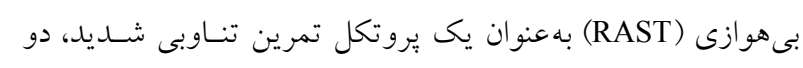

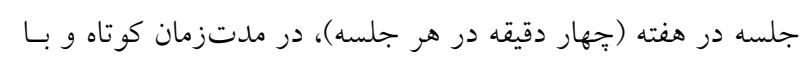

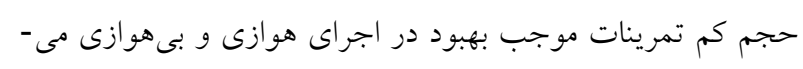

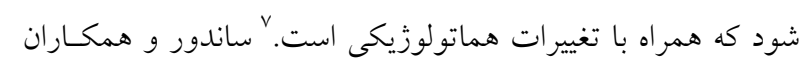

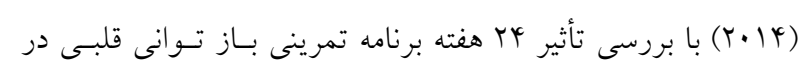

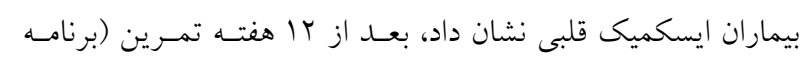

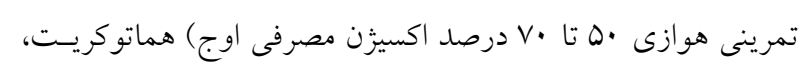

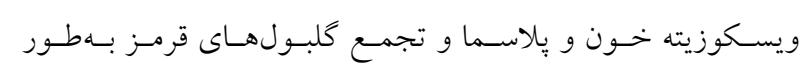

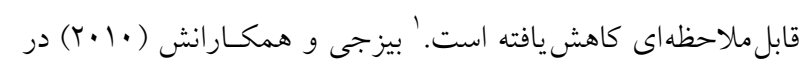

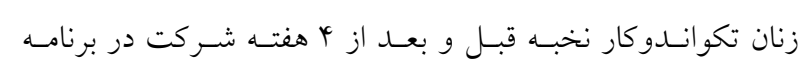

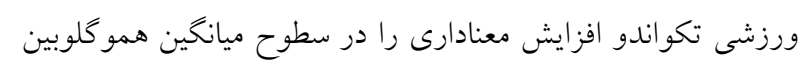

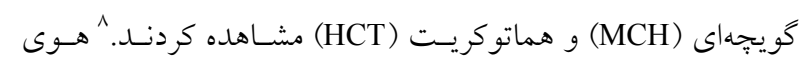

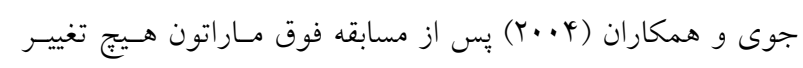

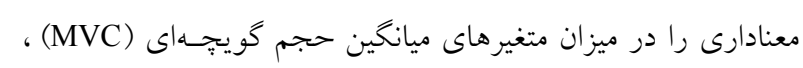

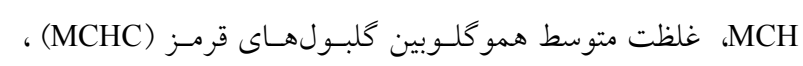

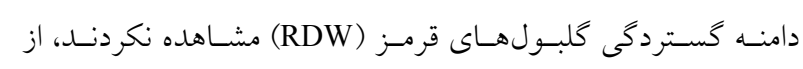

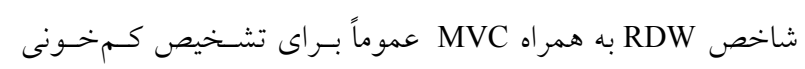


دقيقه استراحت حاصل از استراحتهـاى بـين سـتهـا؛ در كـل دو ساعت را صرف زمان تمرين كرد. براى كروه HIIT2 در طول جهار

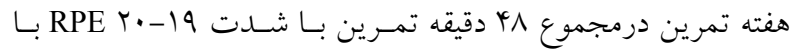

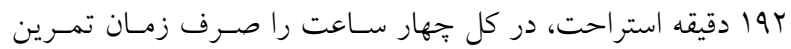

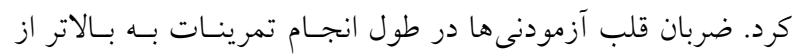

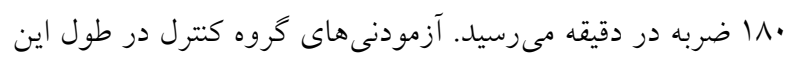
جهار هفته هيج گونه فعاليتى نداشتند.

\section{جمع آورى نمونهها}

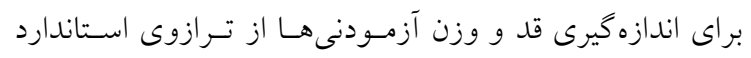

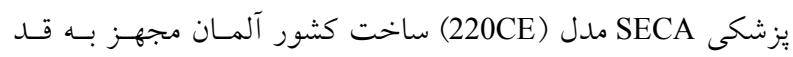

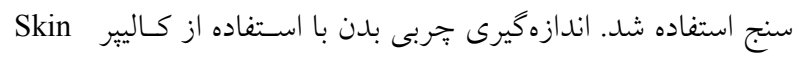

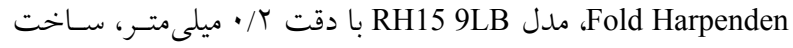
كشور انخليس به روش خينيوستى سهنقطـهاى جكسـون - يـولاى

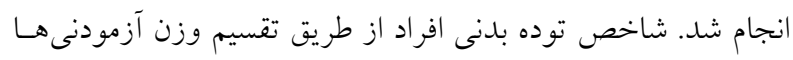

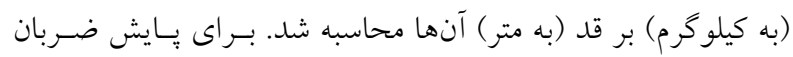

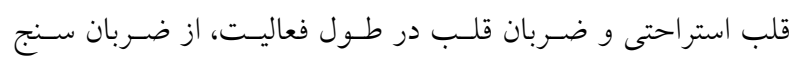
Beurer مدل M80 ساخت كشور آلمان استفاده شد.

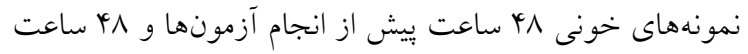

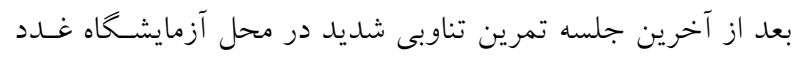

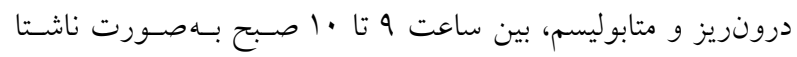

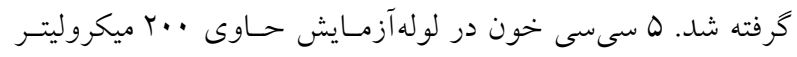

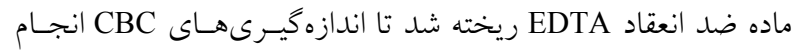

\section{روشهاى آمارى}

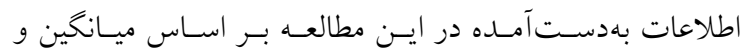
انحراف استاندارد كزارششده است. كليه عمليات آمارى با استفاده

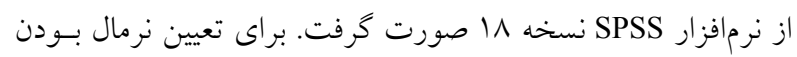

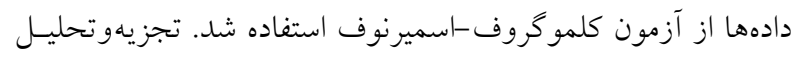

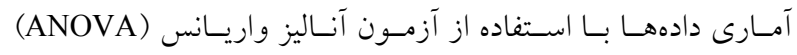

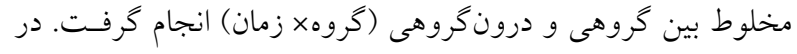

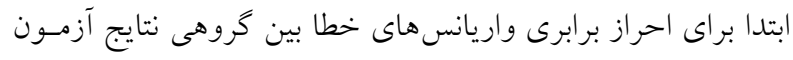

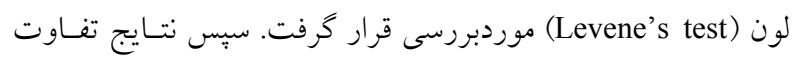

يزّوهش را تكميل نمودند. برسشنامه سلامتى و ميزان فعاليت توسط

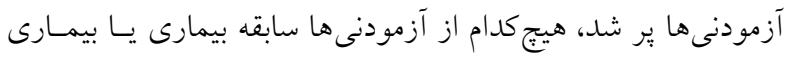

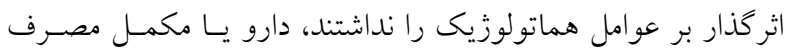

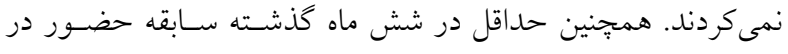

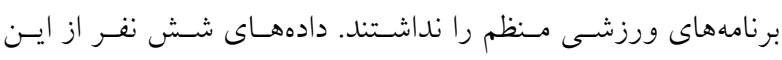

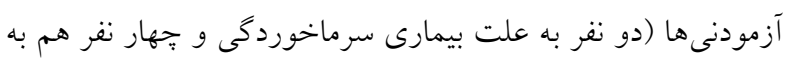

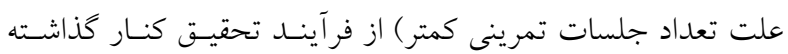

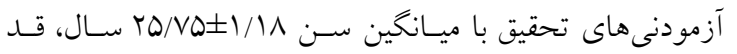

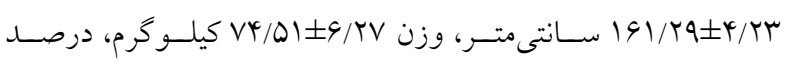
جربس س r/T/99

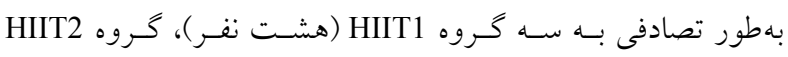

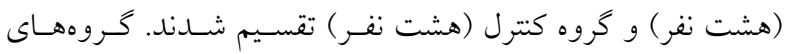
تجربى جهار هفته تمرين تناوبى شديد را با شدت 19 الى •ب ميزان

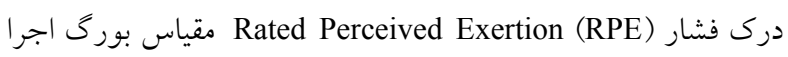

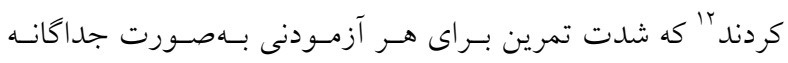

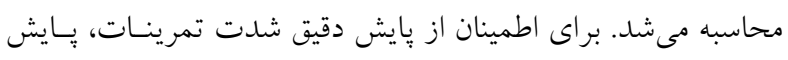
ضربان قلب هم مدنظر قـرار مسى گرفـت. بـراى بررسى آزمونسهاى

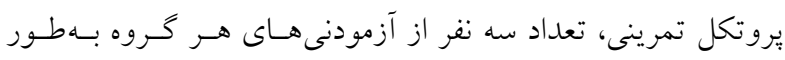

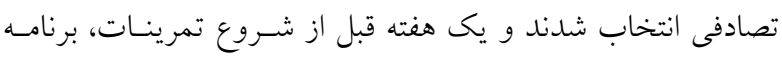

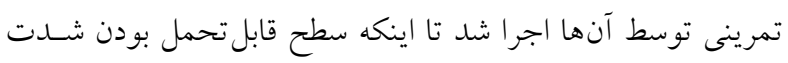

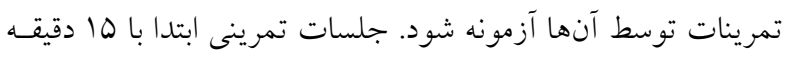

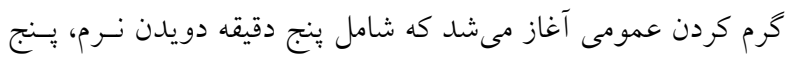
دقيقه تمرينات كششى يويا و ينج دقيقه حركات جهشى و وانفجـارى

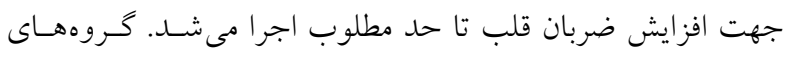

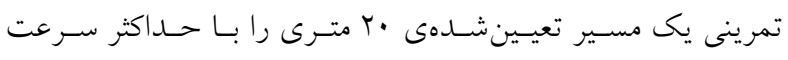

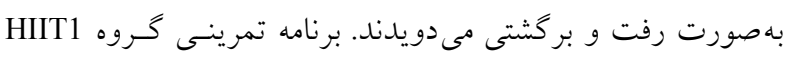
بهصورت سه جلسه در هغته و هر جلسـه جهـار سـت ·r ثانيـاى

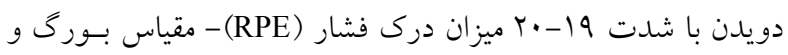

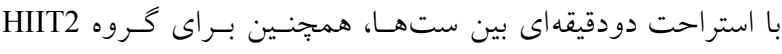

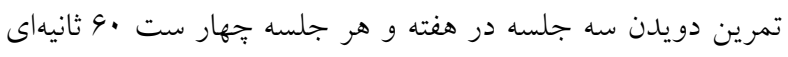

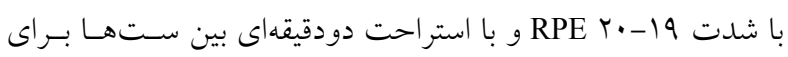

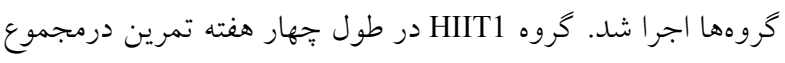

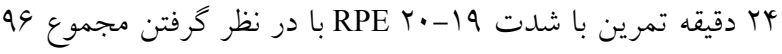


متغيرها همر اه بــا انــازه اثـر مداخلـه تمرينسى و سـطح معنسى دارى

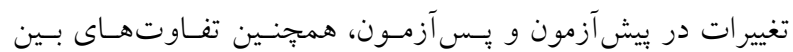
كروهها را نشان مىدهل.

جدول ا: مشخصات دمو گر افيك آزمودنىهـا (ميـانگين و انحـراف

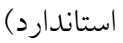

\begin{tabular}{|c|c|c|c|}
\hline گروه كنترل & كروه HIIT2 & كروه HIIT1 & متغير \\
\hline $19 Y / 0 \cdot \pm r / 9 V$ & $109 / T \Delta \pm \Delta / \wedge q$ & $|G T /| r \pm r / A D$ & قد (cm) \\
\hline$V Q / \pm Q / 4)$ & $V Y / \Delta 1 \pm 0 / 19$ & $\vee \varepsilon / \cdot r \pm \Lambda / \cdot q$ & وزن (kg) \\
\hline$r \Delta / r \Delta \pm 1 / \cdot r$ & $r G / G Y \pm 1 / r$. & $r Q / M V \pm \cdot / V Y$ & سن (سال) \\
\hline$\Gamma / / \Delta \Delta \pm \Gamma / \wedge \Delta$ & $r \cdot / 4 \cdot \pm 1 / v q$ & $r \cdot / r q \pm r / \cdot q$ & درصد جِبى \\
\hline$\Upsilon \wedge / \Gamma \wedge \pm 1 / \vee$. & $r \wedge / V Q \pm I / \wedge q$ & $r N / A V \pm Y / T V$ & BMI \\
\hline
\end{tabular}

بين گروه ها بررسى شد. در صورت معنىدارى تفاوت بين گروهها،

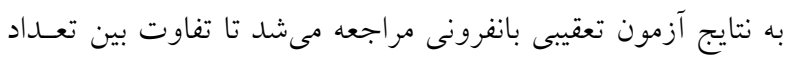
مقايسهها مشخص گردد. مقدار خطا در سطح معنىدارى (ه•/•>م) محاسبه شد.

\section{بافته ها}

بررسى آزمون كولموكروف-اسميرنوف نشان داد، توزيع تمـام

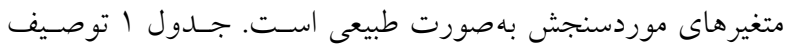
آمارى مشخصات فردى آزمودنى ها در هر گروه (ميانخين \pm انحراف استاندارد) را نشان مىدهد. جدول ب ميـانخين و انحـر اف اسـتاندارد

جدول Y: ميانخين، انحراف استاندارد و نتايج تجزيهوتحليل استنباطى متغيرهاى تحقيق در بيشآزمون و يسآزمون

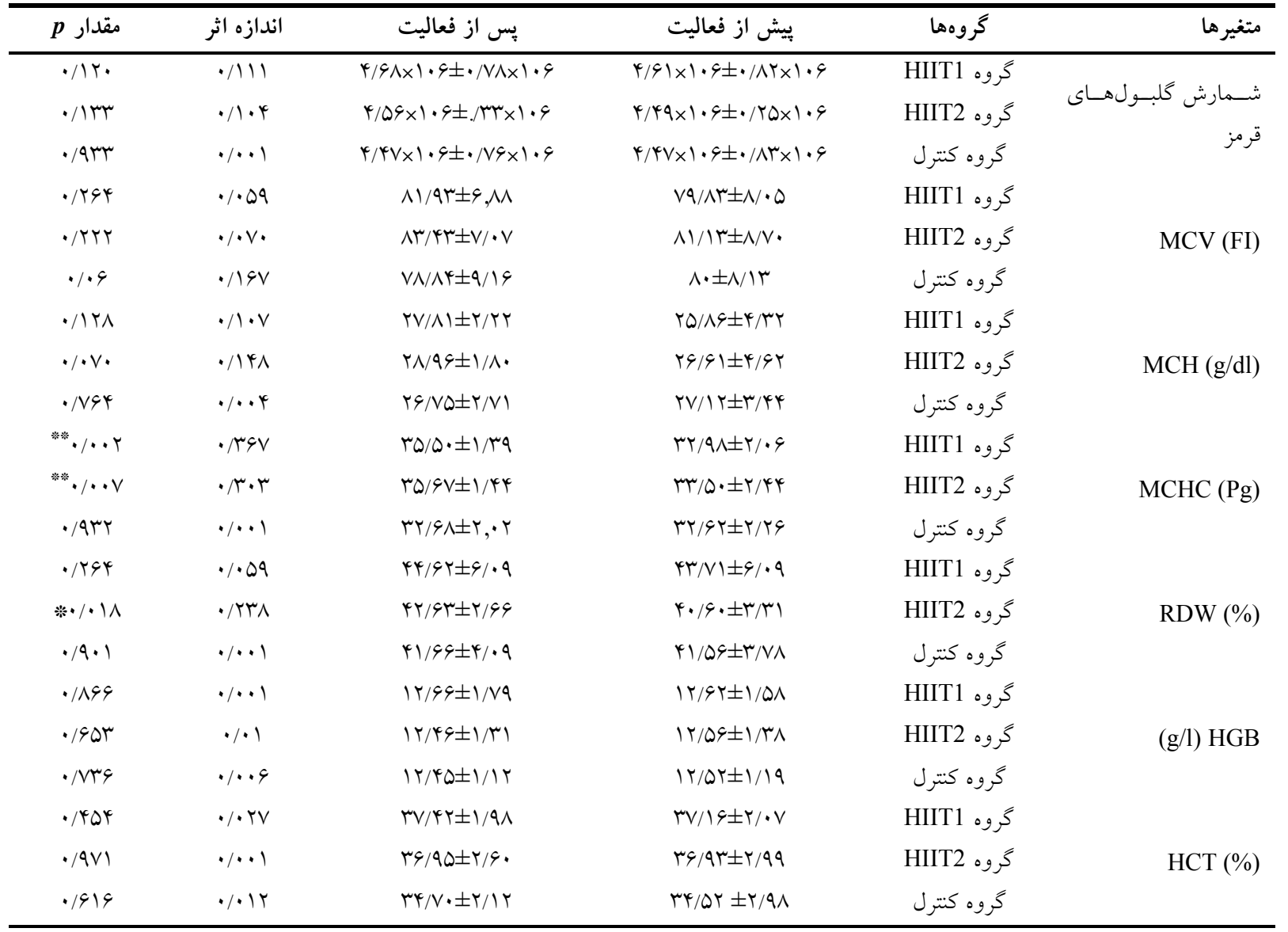

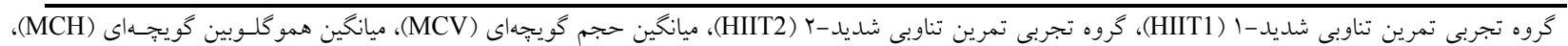

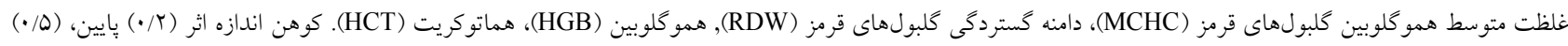

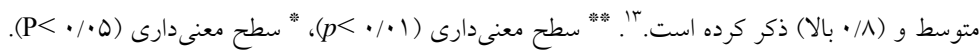




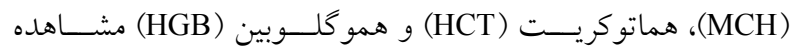
نكرديم. با اين حال براثر تمرين ما شاهد افزايش تقريبى ك درصدى

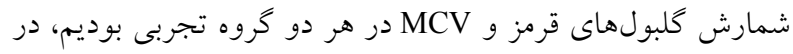

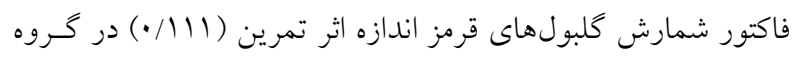

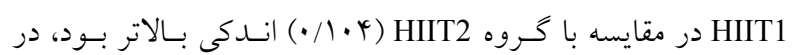
ميانكين شاخص MCH به ترتيب شاهد افزايش V درصدى در كروه

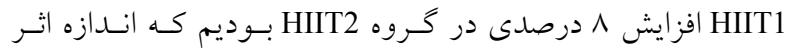

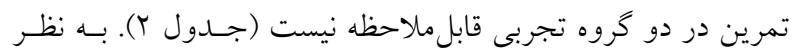

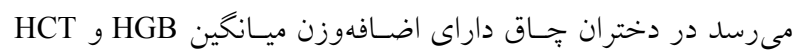
خيلى تحت تأثير تمرينات شديد كوتاهمدت قرار نمى كيرد يا حداقل

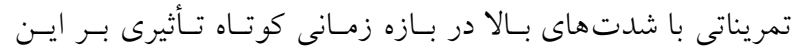

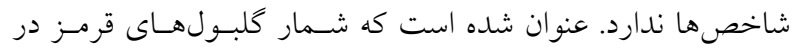

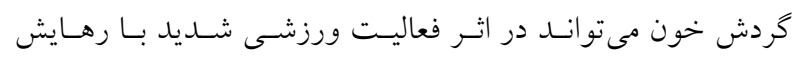

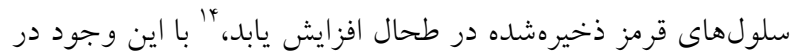

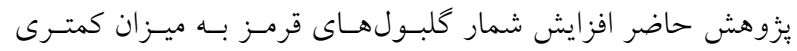

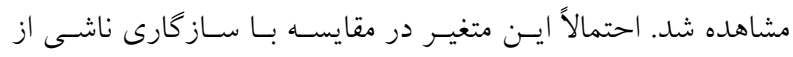

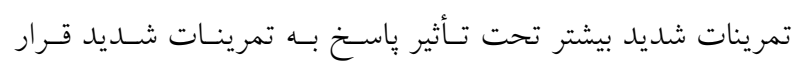

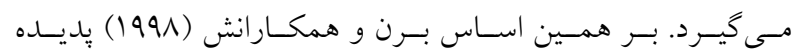

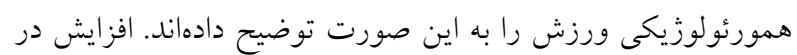

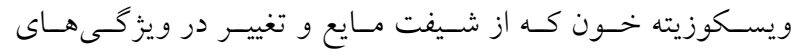

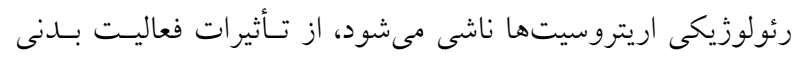

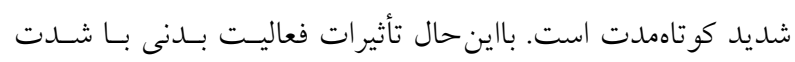

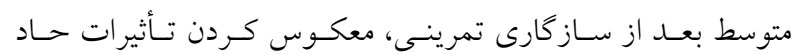
فعاليت ورزشى است كه با افزايش جريـان خـون و حجــم بِاســما

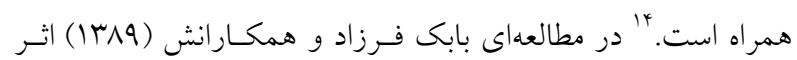

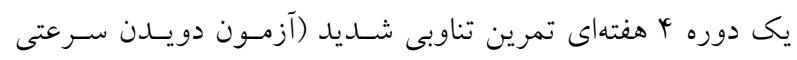

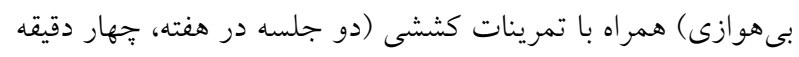

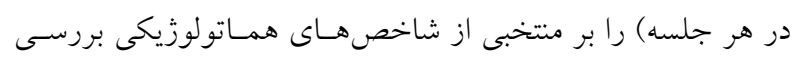

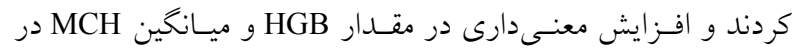
كروه تجربى مشاهده كردند. حال اينكـه در يافتـهــاى مـا افز ايش

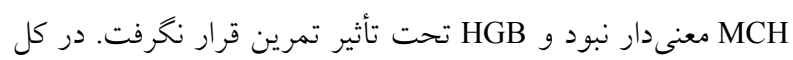

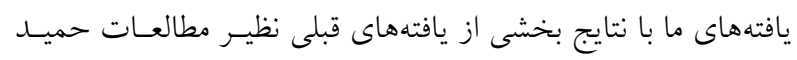

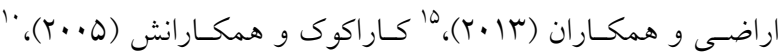

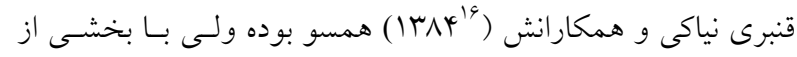

در فاكتورهاى تعداد كلبولهاى قرمز، HGB MCH MCV ، MCT

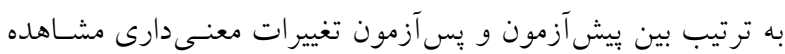

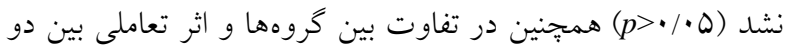

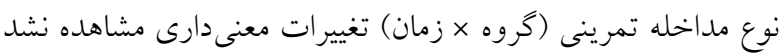

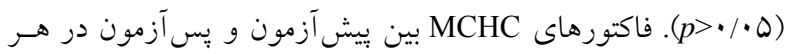

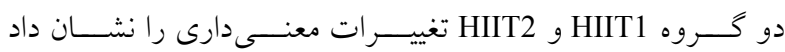

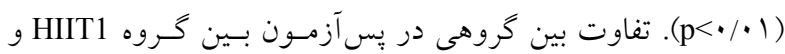

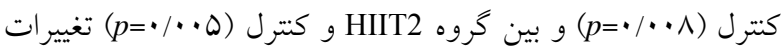

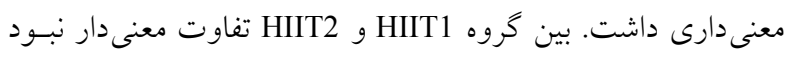
(p=1/.•)

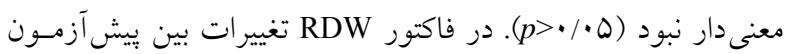

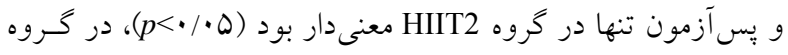
HIIT1

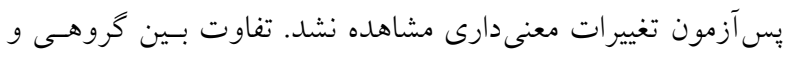

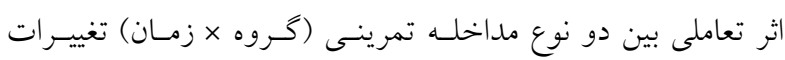

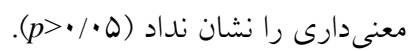

در ميـانخين غلظـت MCHC مـا شـاهد افـزايش معنسىدار V V

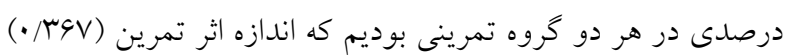

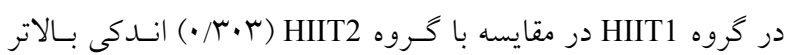
است، همجنين مشاهده مى كنيم كه اندازه اثـر تمـرين هـر دو كـروه تجربى در حد متوسط مىباشد، در ميانكين RDW ما شاهد افـزايش

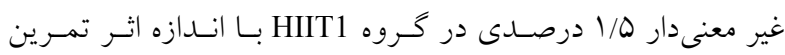

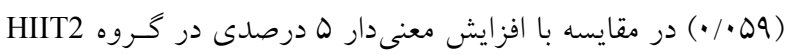

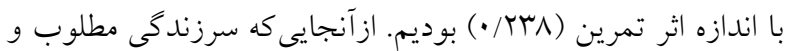

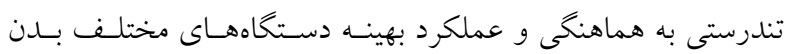

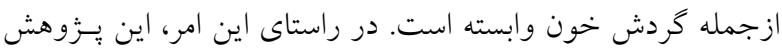

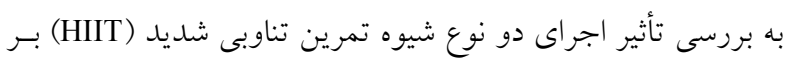

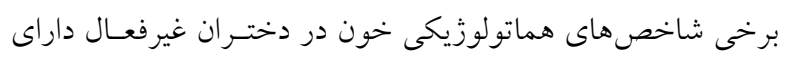

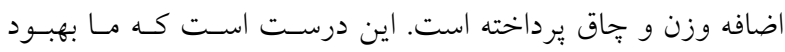
معنى دارى را در برخى شاخصها مثل شمارش كلبـولهـاى قرمـز،

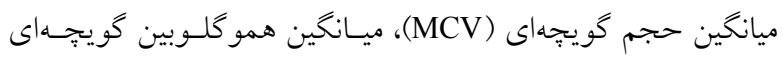




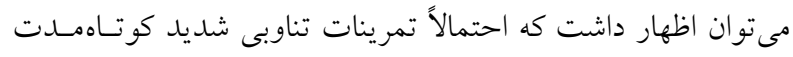

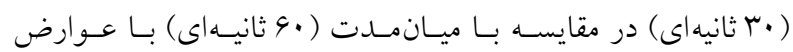

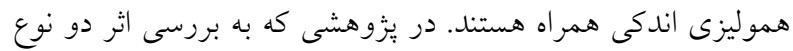

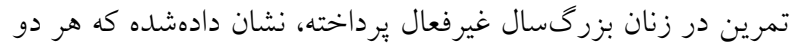

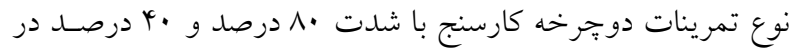

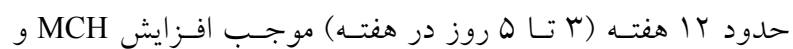
MCHC

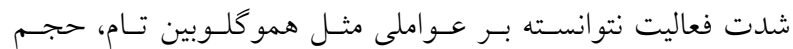

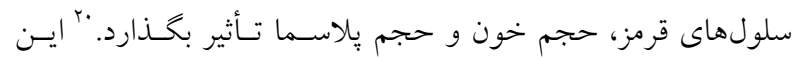

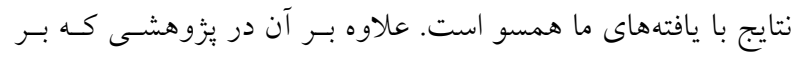

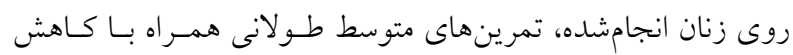

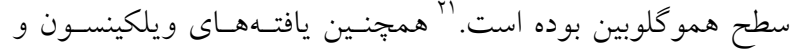

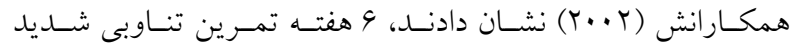
(تمرينات تناوبى شديد به همراه تمرينات استقامتى ه روز در هغته)

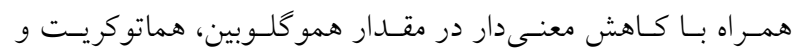

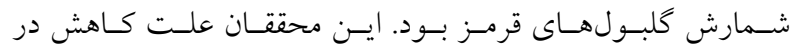
همو كملوبين را كاهش در هماتوكريت ذكر كردهاند. اين نتايج بيشنهاد

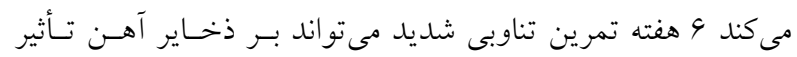

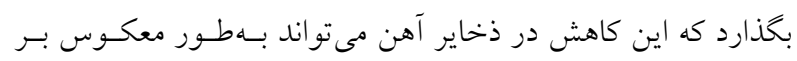

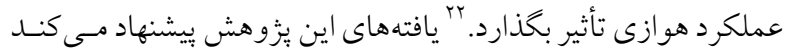

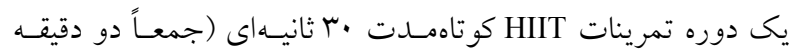
تمرين در هر جلسه) در مقايسه با HIIT ميانمدت •9 ثانيـه (جمعساً

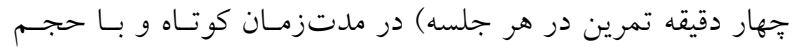

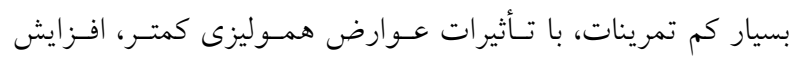

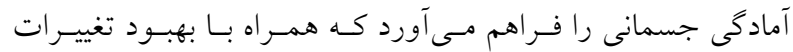
هماتولوزيكى بر عملكردهاى هوازى و بى هوازى مؤثر خواهد بودا.

\section{References}

1. Sandor B, Nagy A, Toth A, et al. Effects of Moderate Aerobic Exercise Training on Hemorheological and Laboratory Parameters in Ischemic Heart Disease Patients. PloS one. 2014;9(10):e110751.

2. Corrà U, Piepoli MF, Carré F, et al. Secondary prevention through cardiac rehabilitation: physical activity counselling and exercise training Key components of the position paper from the Cardiac Rehabilitation Section of
يافتسههــاى زيبــو و همكــارانش ( •199)، باربــارا و همكــارانش

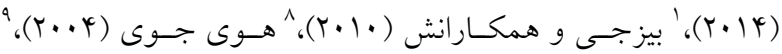

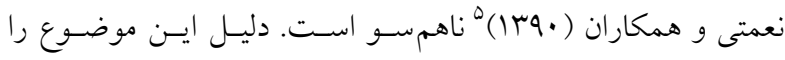
مىتوان در برخى از تفاوتها مثل نوع تمرينات استفادهشده، شـدت تمرينات، جنسيت و سطح آمادگى آزمودنى ها جستجو كرد. با توجه به اين كه در برخى مطالعات آزمودنىها را ورزشكاران تمرين كرده

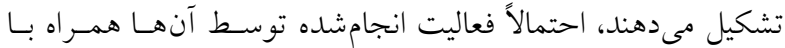
فر آيند هموليز بوده است. جنانجه بوياجيوف و همكـارانش ( (Y... كزارش كردند در ورزشـكاران تمـرين كـرده، در مقايسـه بـا افـراد تمرين نكرده تعداد سلولهاى قرمز و همو كلوبين بايينترى مشاهده

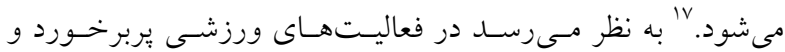
فعاليتهاى شديد، به دليل افـزايش همـوليز كـاهش معنــادارى ايسن متغيرها قابل توجيه باشد. از غلظت شاخصهـاى MCHC MCH و مDW

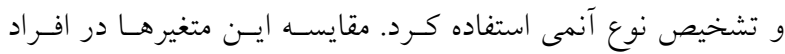
ورزشكار و غير ورزشكار تفاوت قابلملاحظهاى را نشان مىدهد كه

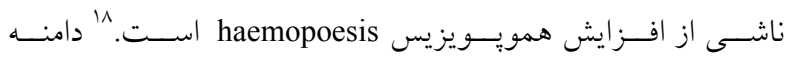
يراكندگى كلبولهاى قرمز در تمامى انواع آنمىها (ناشى از ورزش، فقر آهن، كمبود ويتامين B و كمبود اسيدفوليك) افزايش مي يابد؛ كه

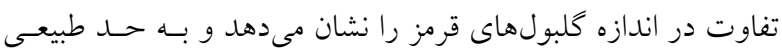
رسيدن آن، نشانه به حد طبيعى رسيدن ذخاير مغز استخوان است. 19 با توجه به نتايج (جدول r) دامنه براكنـدگى گلبـولهـاى قرمـز در مطالعه حاضر تنها در گروه HIIT2 افزايش معنسى دارى را نشـان داد. به نظر مىرسد در فرآيند هموليز و تغييـرات در خلبـولهــاى قرمـز خون، نوع HIIT (كو تاهدل، ميانمدت و طولانى مدت) بــهــاربرده

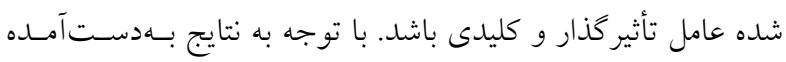

the European Association of Cardiovascular Prevention and Rehabilitation. European heart journal 2010;31(16):1967-74.

3. Connes P, Simmonds MJ, et al. Exercise hemorheology: classical data, recent findings and unresolved issues. Clinical hemorheology and microcirculation 2013;53(1):187-99. 
4. Szygula Z. Erythrocytic system under the influence of physical exercise and training. Sports Medicine 1990;10(3):181-97.

5. nemati Gho, rahmani nia F,mirzaei B. The effect of Eccentric contraction on blood hematological changes in young male nonathletes. Exercise Physiology 2009;15:71-82.[In Persian].

6. Koc H, Tekin A, Ozturk A, et al. The effect of acute exercises on blood hematological parameters in handball players. African Journal of Microbiology Research 2012;6(9):2027-32.

7. Babak F, Gharakhanlou R, Bayat M, et al. the effect of intense interval training on the selection of indicators of aerobic, anaerobic and hematological athletes. Research in Sport Science 2008, 10.8-69.[In Persian].

8. BEZCI Ş, KAYA Y. The Analyze of Hematological Parameters of Elite Women Taekwondoers before and after Training. Pamukkale J Sport Sci. 2010;1(2):1-16.

9. Wu H-J, Chen K-T, Shee B-W, et al. Effects of $24 \mathrm{~h}$ ultramarathon on biochemical and hematological parameters. World Journal of Gastroenterology 2004;10(18):2711-4.

10. Karakoc Y, Duzova H, Polat A, et al. Effects of training period on haemorheological variables in regularly trained footballers. British journal of sports medicine 2005;39(2):e4-e.

11. Ghanbari Niaki A, Mohammadi S. Effect of 4 Weeks of an Aerobic (RAST) Training on Hematological Changes In Male Kick-Boxers. Journal of Applied Exercise Physiology (Journal of Sports Science) 2010;5(10):75-87.

12. Borg G. Simple rating methods for estimation of perceived exertion. Physical work and effort. 1976:39-46.

13. Pallant J. SPSS survival manual: A step-by-step guide to data analysis using SPSS version 15. Maidenhead, Berkshire, England: McGraw-Hill Education. 2007.
14. Brun J, Khaled S, Raynaud E, et al. The triphasic effects of exercise on blood rheology: which relevance to physiology and pathophysiology? Clinical hemorheology and microcirculation 1998;19(2):89-104.

15. arazi $\mathrm{H}$, rahmati $\mathrm{S}$, pahlevan zade $\mathrm{m}$. the effect of a specialized training session on hematologic indices in Aerobic Gymnastics national team of Iran. Journal of Applied Biological Sciences in Sports 2011.(1).58-69

16. Ghanbari niaki A. The effects of circle resistance training sessions on hematological changes Physical education students. J Sports Scie 2003;(2).77-88 [In Persian].

17. Arazi H, Salehi A, Hosseini Y, et al. The response of hematological factors to a circuit resistance training program with various intensities in athlete male students. Scientific Journal of Iranian Blood Transfusion Organization 2012;9(1).

18. Joksimović A, Stanković D, Ilić D, et al. Hematological profile of Serbian youth national soccer teams. Journal of human kinetics 2009;22:51-9.

19. Ashenden M, Pyne D, Parisotto R, et al. Can reticulocyte parameters be of use in detecting iron deficient erythropoiesis in female athletes? The Journal of sports medicine and physical fitness 1999;39(2):140-6.

20. Branch 3rd J, Pate R, Bourque S, et al. Exercise training and intensity does not alter vascular volume responses in women. Aviation, space, and environmental medicine 1999;70(11):1070-6.

21. Preziosi P, Prual A, Galan P, et al. Effect of iron supplementation on the iron status of pregnant women: consequences for newborns. The American journal of clinical nutrition 1997;66(5):1178-82.

22. Wilkinson J, Martin D, Adams A, et al. Iron status in cyclists during high-intensity interval training and recovery. International journal of sports medicine 2002;23(8):544-8 